HERNÁEZ ESTEBAN, E., «La Corte penal internacional: un reto contra la impunidad», REDUR I4, diciembre 20I6, págs.

I9I-2I7. ISSN i695-078X

\title{
LA CORTE PENAL INTERNACIONAL: UN RETO CONTRA LA IMPUNIDAD
}

\author{
Elena HERNÁEZ ESTEBAN \\ GRADUADA EN DERECHO \\ UNIVERSIDAD DE LA RIOJA
}

SUMARIO: I. Introducción. II. Creación y caracteres de la Corte. II.I. La responsabilidad internacional del individuo. II.2 Proceso de creación de la Corte. II.3 El Estatuto de Roma y las características de la Corte. III. Jurisdicción y competencias. III.I. Requisitos competenciales. III.2. Límites a su competencia. III.3. Competencias. III.3.I. Ratione personae. III.3.2. Ratione materiae. III.3.2. I. Crimen de Genocidio. III.3.2. 2. Crímenes de lesa humanidad. III.3.2. 3. Crímenes de guerra. III.3.2. 4. Crimen de agresión. III.3.2. 5. ¿Crimen de terrorismo internacional? III.3.3. Ratione temporis. IV. La Corte Penal Internacional y el Consejo de Seguridad: el mantenimiento de la paz y la seguridad internacionales. IV.r. Legitimación del Consejo de Seguridad para remitir situaciones a la Corte. IV. 2. Facultad del Consejo de Seguridad para ampliar la competencia de la Corte. IV.3. Facultad de suspensión del Consejo de Seguridad. IV.4. El Consejo de Seguridad como garante de la cooperación Estatal. IV.5. El consejo de Seguridad y la determinación de un acto de agresión. V. Conclusiones. VI. Tabla de abreviaturas.

RESUMEN: Este trabajo versa, esencialmente, sobre el estudio de la Corte Penal Internacional como mecanismo de erradicación de la impunidad de aquellos crímenes que afectan a la humanidad en su conjunto. Para una correcta comprensión de la materia, analizaremos el proceso de humanización llevado a cabo en el Derecho Internacional, así como los antecedentes y características de la Corte. Posteriormente estudiaremos su jurisdicción y competencias y, por ende, los crímenes o potenciales crímenes sobre los que puede actuar. Y, finalmente, ahondaremos en las -problemáticas- relaciones existentes entre la Corte con el Consejo de Seguridad.

Palabras Clave: Corte Penal Internacional, Estatuto de Roma, Consejo de Seguridad, Crímenes más graves de Derecho Internacional, Responsabilidad internacional del individuo

ABSTRACT: This essay deals on the study of the International Criminal Court as a mechanism to eradicate impunity for those crimes that affect humanity as a whole. For a better understanding of the matter, we will first analyse the humanisation process carried out in International Law and the backgrounds and features of the Court. Further along, we will study its jurisdiction and powers, therefore, we will also study the crimes or potential crimes over which it can exercise its jurisdiction. Finally, we will delve into the problematic relationship between the Court with the Security Council.

KeYwords: International Criminal Court, Rome Statute, Security Council, The most serious crimes in International Law, International criminal responsibility of the individual 


\section{Introducción}

Los años de tránsito entre el siglo XX y el XXI, como diría ESCOBAR HERNÁNDEZ, «están impregnados de una suerte de contradicción casi esquizofrénica» ${ }^{\mathrm{I}}$. Esto es así, en la medida en que se produjeron importantes avances en la humanización de las relaciones internacionales, pero a su vez, el número de conflictos armados incrementaba de forma exponencial, viéndose afectados los valores más básicos de la humanidad.

En los cambios acontecidos debemos reconocer el papel que ha jugado la tecnología, la cual contribuyó tanto a que las barreras comerciales, fronterizas, técnicas, físicas etc. que existían antaño se disiparan, como a que el ser humano en la actualidad pueda hacer un sinfín de cosas que, aunque ahora resulten cotidianas, años atrás parecerían sacadas de una novela de ciencia ficción. Así, a día de hoy las personas podemos viajar por tierra, mar y aire a una velocidad increíble, podemos ir al espacio exterior, podemos realizar impresiones en 3D, podemos hacer fotos y guardar los recuerdos en «la nube» $y$, es que efectivamente, a veces, la realidad supera a la ficción.

Sin embargo, desgraciadamente, no todo han sido avances en positivo puesto que también se han desarrollado nuevos armamentos, nuevas estrategias de combate y los avances tecnológicos han permitido dotar a la guerra de una gran capacidad de devastación, demostrándose así mismo la capacidad del ser humano para cometer crímenes atroces que desafían a la imaginación y conmueven a la humanidad.

Por ese motivo, aun siendo cierto que el uso de la violencia no ha sido inusual a lo largo de la Historia, el salto cualitativo y cuantitativo que se produjo en la dureza de los crímenes supuso un punto de inflexión por el cual se aunaron esfuerzos para lograr la creación de una jurisdicción penal internacional que tuviera como objetivo, no sólo acabar con la impunidad de los autores de esos crímenes, sino también contribuir a la prevención de los mismos en el futuro.

De esta forma, el propósito del presente trabajo consiste en el análisis de la Corte Penal Internacional -como tribunal internacional penal permanente con competencias sobre los crímenes más graves de trascendencia internacional- y en el examen de la incidencia que tiene el Consejo de Seguridad en el cumplimiento de los objetivos de la Corte, por ello el trabajo se estructura en tres bloques claramente diferenciados:

En el primero de ellos, realizaremos un estudio del proceso de humanización que se ha llevado a cabo en el Derecho Internacional, pasando por un análisis de los antecedentes de la Corte, así como de las características de las que se le dotó. Este bloque nos proporcionará un primer acercamiento a la Corte y nos permitirá una mejor comprensión de los posteriores. No cabe duda de que, conocer el pasado nos permite, además de entender el presente, atisbar hacia donde se puede avanzar en el futuro en un tema de tanta relevancia como es la lucha contra la impunidad y, por ende, la defensa de los derechos

\footnotetext{
${ }^{\text {I}}$ Escobar Hernández, C., «La Corte Penal Internacional: un instrumento al servicio de la paz», RIFP, núm. 2I, 2003, págs. 5 a 35 y en especial pág. 5 .
} 
humanos. Por ese motivo, también se hará alusión a cuestiones de gran actualidad como es el conflicto armado sirio o el crimen de terrorismo internacional.

En el segundo bloque estudiaremos la jurisdicción y competencias de la Corte Penal Internacional. Por tanto, analizaremos los requisitos, límites y ámbitos sobre los que ejerce su competencia. El estudio de este bloque implica el análisis de los principios a los que se somete, haciendo especial referencia al principio de complementariedad y, el examen de los crímenes más graves de trascendencia internacional.

Por último, en el tercer bloque, analizaremos la controvertida relación existente entre el Consejo de Seguridad, como órgano político de las Naciones Unidas, y la Corte.

\section{Creación y caracteres de la Corte}

II.I. La responsabilidad penal internacional del individuo

Es bien sabido que el Derecho Internacional clásico no contemplaba al individuo como sujeto de Derecho Internacional (DI) razón por la cual los individuos no tenían reconocidos derechos pero tampoco obligaciones $y$, por ende, no era posible exigir su responsabilidad con motivo de violación de una norma de DI.

La responsabilidad penal internacional del individuo se vincula inexorablemente a la posición que el ser humano ocupa en el seno del DI y por eso no fue hasta la hecatombe acaecida en la II Guerra Mundial cuando se le reconoció -limitadamente- subjetividad internacional.

Dicho reconocimiento supuso un gran cambio respecto al panorama anterior y, como consecuencia de la humanización del DI, se fueron reconociendo una serie de derechos a los individuos -Carta San Francisco de 1945, Declaración Universal de I948, los Pactos Internacionales de Derechos Civiles y Políticos y de Derechos Económicos, Sociales y Culturales de i996-, sin embargo se debatía acerca de cuáles serían los mecanismos para alcanzar el cumplimiento de tales derechos, o dicho de otra forma, qué ocurría en caso de violación de los mismos. En ese sentido, la opinión pública tomo conciencia de que los «graves crímenes constituyen una amenaza para la paz, la seguridad y el bienestar de la humanidad» ( $\mathbb{5} 5$ del Preámbulo ER) y se abogó por el establecimiento de una Corte permanente que sancionase esos delitos y evitara que los peores pasajes de la historia volvieran a repetirse en el futuro².

\section{II.2. Proceso de creación de la Corte}

El inicio del proceso de institucionalización de la justicia penal internacional debemos ubicarlo en el Proyecto Gustave Moynier de 1872, mediante el que se proponía la

\footnotetext{
2CArdona lloréns, J., «Presentación», en Gómez Colomer, J.L., González CussaC, J.L. y Cardona Lloréns, J. (Coords.), La Corte Penal Internacional (Un estudio interdisciplinar), Valencia, Tirant lo Blanch, 2003, págs. I5 a I9.
} 
creación de una instancia judicial internacional permanente para juzgar los crímenes más graves de trascendencia para la comunidad internacional en su conjunto.

Dicho proceso continuo tras la I Guerra Mundial cuando en el Tratado de Versalles de 1919 se estableció la creación un tribunal internacional para la persecución y castigo de los más altos mandos ${ }^{3}$ por las violaciones de los «principios de derecho de gentes tales como resultan de los usos establecidos entre Naciones civilizadas, de las leyes de la humanidad y de las exigencias de la conciencia pública» ${ }^{4}$.

Con posterioridad, durante el período de entreguerras se propuso la creación y establecimiento de un Alto Tribunal de Justicia Internacional y las opiniones doctrinales empezaban a decantarse por el reconocimiento de una cierta subjetividad al individuo. Además, gracias a la Sociedad de Naciones, también se avanzó hacia la prohibición del uso de la fuerza con el Pacto Briand-Kellogg, mediante el cual los Estados se comprometían a renunciar a la guerra como instrumento de política nacional y se declaraba la ilicitud general de la guerra 5 .

Pese a las buenas intenciones de este Pacto, no se pudo evitar la producción de otra conflagración mundial, y es aquí cuando nos presentamos ante los antecedentes inmediatos de la CPI.

Tras la II Guerra Mundial se produjo un cambio radical en la conciencia internacional y se clamaba la creación de una justicia ejemplar contra los desmanes producidos, así se crearon los primeros tribunales internacionales, los tribunales ex post factum $y$ ad hoc de Nüremberg y Tokio.

El Tribunal Militar Internacional de Nüremberg (TMIN) se creó el 8 de agosto de I945 mediante el Acuerdo de Londres relativo al procesamiento de los grandes criminales de guerra de las potencias del Eje y su competencia se extendía sobre aquellas personas que hubieran cometido delitos contra la paz, crímenes de guerra que violaran leyes y costumbres de guerra o delitos de lesa humanidad. Por su parte, el Tribunal Militar Internacional para el Extremo Oriente o Tribunal de Tokio (TMIT) se sirvió para su creación del anterior tribunal -aunque entre ambos existían diferencias-, y se constituyó a través de una Ordenanza del General Douglas MacArthur el i9 de enero de i946.

\footnotetext{
${ }^{3}$ Cid MuÑoz, M.I.: Pese a ello, Holanda no extraditó al Káiser Guillermo II y, respecto a los dirigentes alemanes, «las sentencias que se dictaron establecieron castigos irrisorios (...) por el reconocimiento de ciertas defensas jurídicas (...) que les eximían de responsabilidad, como la 'la obediencia debida'», (La Corte Penal Internacional: un largo camino, Madrid, Dykinson, 2008, pág. I8). Esto contrasta con lo que estudiaremos con posterioridad en relación con la competencia ratione personae de la CPI.

${ }^{4}$ Cláusula Martens (Preámbulo del Convenio II de La Haya de I899 relativo a las leyes y costumbres de la guerra terrestre).

${ }^{5}$ El Pacto general de renuncia a la guerra, más conocido como Pacto Briand-kellogg, establecía el compromiso de renunciar a la guerra «como instrumento de política nacional», sin embargo permitía excepciones y carecía de mecanismos institucionales que garantizaran su cumplimiento, por ese motivo fue incapaz de impedir el desencadenamiento de diversos incidentes bélicos y, en especial, el de la II Guerra Mundial. Diez De VeLASCO, M., Instituciones de Derecho Internacional Público, I8ª ed., Madrid, Tecnos, 20I3.pág. Io69.
} 
A pesar de que estos primeros Tribunales no participaban stricto sensu de la naturaleza propia de una jurisdicción ${ }^{6}$ y de que se les tachara de «justicia de los vencedores sobre los vencidos», hay que reconocer la relevancia que han tenido, ya que como puso de manifiesto YÁNEZ-BARNUEVO, «Primeramente, se demostró que era factible una justicia penal internacional que evitase tanto la pura y simple venganza como la simple impunidad (...). En segundo lugar, al centrar las responsabilidades en los dirigentes y en los principales ejecutores, apartó el fantasma de la «culpabilidad colectiva» (...). Finalmente, estableció unas pautas conforme a las cuales habría de juzgarse en el futuro el comportamiento de responsables políticos o autoridades militares de cualquier país (...)»

Además, como manifestaba la sentencia del TMIN de i de octubre de I946, «(...) los crímenes contra el derecho internacional se cometen por hombres (...) y sólo castigando a las personas que cometen dichos crímenes se pueden hacer cumplir las disposiciones del derecho internacional» ${ }^{8}$.

En este proceso de lucha contra la impunidad también debemos hacer referencia a los Tribunales Penales Internacional para la antigua Yugoslavia (TPIY) y para Ruanda (TPIR) ${ }^{9}$ creados por el Consejo de Seguridad (CS) bajo el amparo del Capítulo VII de la Carta de Naciones Unidas mediante las resoluciones 827 (I993) de 25 de mayo de I993 y 955 (I994) de 8 de Noviembre de I994, respectivamente.

Por último, debemos traer a colación a las Cámaras Africanas Extraordinarias, ya que, aunque no se configuran como antecedente propiamente dicho de la CPI, han supuesto un paso de gigante hacia la lucha contra la impunidad. Así, el pasado 30 de mayo de 2016 se dictó sentencia condenatoria a cadena perpetua contra el ex dictador Hissene Habré por los crímenes cometidos en Chad desde el 7 de junio de 1982 hasta el I de diciembre de 1990 , periodo durante el cual estuvo al poder ${ }^{\mathrm{ro}}$.

\footnotetext{
${ }^{6}$ Cabezudo Rodríguez, N., La Corte Penal Internacional, Madrid, Dykinson, 2002, pág. 22.

${ }^{7}$ YÁneZ-BARnUeVo, J.A., «La Conferencia de Roma y el Estatuto de la Corte penal Internacional; balance y perspectivas», en EscobAR HeRnÁNDEZ, C. (Ed.), Creación de una jurisdicción penal internacional, Madrid, BOE, Colección Escuela Diplomática núm. 4, 2000, págs. I7 a 28 y en especial pág. I9.

${ }^{8}$ Trial of the Major War Criminals Before the International Military Tribunal: Nüremberg 14 November $1945-1$ October 1946, International Military Tribunal, Nüremberg, I967, vol. I, pág. 223. (Disponible en: https://www.loc.gov/rr/frd/Military_Law/pdf/NT_Vol-I.pdf, última consulta el I8/05/20I6). En el mismo sentido véase TIPY, Prosecutor v. Tadic, de 2 de octubre de 1995 (Caso núm. IT-94-I), Decision on the Defence Motion for Interlocutory Appeal on Jurisdiction, Appeal Chamber Decisions, \I29.

${ }^{9}$ Informe sobre la situación de los Derechos Humanos en Ruanda A/49/508-S/I994/II57, de I3 de octubre de I994.

${ }^{10}$ Vid., Chambres africaines extraordinaires, Le Parquet Général contre Hissein Habré prononce et resume du jugement dans l'affarire le Parquet General contre Hissein Habre 30 Mai 20I6. (Disponible en:http://www.chambresafricaines.org/index.php/le-coin-des-medias/communiqu\%C3\%A9-de-presse/639document-prononce-et-resume-du-jugement-dans-1\%E2\%80\%99affaire-le-parquet-general-contre-hisseinhabre-30-mai-20ı6.html, última consulta el 9/06/20I6).
} 
II.3 El Estatuto de Roma y las características de la Corte.

Vistos sus antecedentes, estamos en tesitura de comprender su carácter revolucionario, ya que, por una parte su creación se produjo a través de un tratado multilateral en el que se tuvo en consideración a cada uno de los Estados, a diferencia de lo que ocurría con los cuatro tribunales anteriores, en los cuales el resultado provenía de la decisión de unos pocos Estados -en posición de superioridad- y las decisiones se imponían sin requerir el consentimiento de los Estados a los que se dirigían. Por otra parte, a la CPI se le dotó de imparcialidad y de carácter permanente.

Como adelantábamos, la CPI surgió con la aprobación del Estatuto de Roma (ER) en la Conferencia Diplomática de Plenipotenciarios de las Naciones Unidas celebrada durante el I5 de junio al I7 de julio de I998 en la sede de la Organización de las Naciones Unidas para la Agricultura y la Alimentación.

En su negociación, elaboración y aprobación fue decisiva la intervención de un grupo de Estados «afines» o «like minded» ${ }^{\text {II }}$. Sin embargo dicha tarea no fue sencilla puesto que intervinieron países provenientes de distintos sistemas jurídicos ${ }^{\mathrm{I2}}$ y los Estados tuvieron que asumir la cesión de una parte de su soberanía -ius puniendi-. Además, debemos tener en cuenta que el ER equivale a la suma de varios códigos y leyes en el derecho interno incluye normas sustantivas y procesales-.

Pese a las dificultades existentes, el ER entró en vigor el I de julio de 2002 tras

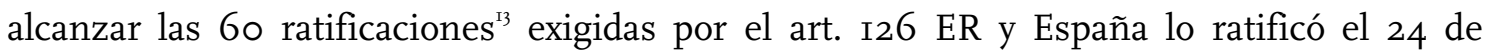
octubre del $2000^{\text {I4 }}$. En la actualidad I39 Estados lo han firmado y I24 lo han ratificado ${ }^{\text {I5 }}$.

De esta forma y en estas condiciones se dio lugar a la creación de la CPI, la cual dispone de una doble naturaleza ${ }^{\mathrm{r} 6}$, en la medida en que es un órgano judicial penal de carácter supraestatal y, a su vez, es una organización internacional.

La CPI ha sido definida como «una institución judicial internacional establecida mediante un instrumento convencional internacional, permanente, independiente, con competencia sobre personas respecto de los crímenes más graves de trascendencia para la

\footnotetext{
${ }^{\text {II }}$ RodRíGuez-VillasAnte Y PRIETO, J.L., «El proceso de aprobación y desarrollo del Estatuto de Roma de la Corte Penal Internacional», Revista Española de derecho Militar, núm. 86, 2005, págs. I6o a I79 y en especial pág. I65. (Disponible en: http://espacioinvestiga.org/wp-content/uploads/20I5/09/DEo0707_Proceso_aprobacion_desarrollo_estatuto_roma-Rodriguez_Villasante.pdf, última consulta el 27/3/20I6).

${ }^{12}$ A/CONF.I83/Io, véase en su Anexo II la lista de los Estados participantes en la Conferencia Diplomática de Plenipotenciarios de las Naciones Unidas sobre el establecimiento de una Corte Penal Internacional.

${ }^{13}$ No es desdeñable el dato de que el ER supero el umbral de las 60 ratificaciones en un período de cuatro años, pues se trata de un plazo bastante breve para un instrumento internacional de tal alcance e implicaciones.

${ }^{14}$ El instrumento de ratificación del Estatuto de Roma de la Corte Penal Internacional fue publicado en el BOE núm. I26, de 27 de mayo de 2002.

${ }^{15}$ Datos extraídos de la página web oficial de la Corte Penal Internacional. (Disponible en: https://asp.icccpi.int/en_menus/, última consulta el I6/4/2016).

${ }^{16}$ Garrido Carrillo, F.J. y Faggiani, V., La aportación de España a la institución de una jurisdicción penal internacional. La Corte Penal Internacional, Granada, Comares, 20I3, pág. 74.
} 
comunidad internacional en su conjunto, predeterminada y obligatoria ${ }^{17}$. A este respecto debemos señalar que la CPI reúne los requisitos de la propios de las Organizaciones Internacionales aunque con matices y por eso se le considera una Organización Internacional sui generis ${ }^{18}$.

\section{Jurisdicción y competencias}

La CPI tiene como objetivo que «los crímenes más graves de trascendencia para la comunidad internacional en su conjunto no queden sin castigo» ( $\mathbb{4} 4$ del Preámbulo ER). Esa finalidad conecta con la de eliminar la impunidad internacional y prevenir la comisión de nuevos crímenes $\left(\mathbb{\int} 5^{\circ}\right.$ del Preámbulo ER). Sin embargo, su competencia para la consecución de tales fines no es ilimitada, por ello al analizar sus competencias debemos hacer mención tanto a los principios a los que se somete como a los a tres niveles en los que ejerce su competencia (ratione materiae, ratione personae y ratione temporis). Obsérvese que en el ER no se determina la competencia de la CPI en relación con su ratione loci, lo cual resulta del todo lógico si se conecta con su vocación de universalidad.

\section{III.I. Requisitos competenciales}

La jurisdicción de la CPI varía en función de cómo se inicie el procedimiento, sin embargo debemos destacar que la CPI no puede actuar de oficio sino que, como dispone el art. I3 ER, será preciso que se le remita una situación por: a) Un Estado Parte; b) Por el Consejo de Seguridad, actuando con arreglo a lo dispuesto en el Capítulo VII de la Carta de las Naciones Unidas; c) El Fiscal.

Por otra parte el art. I2 ER establece una serie de nexos jurisdiccionales o condiciones previas que han de cumplirse para el ejercicio de su competencia: a) Que los Estados sean partes del ER; b) Que el Estado donde se ha cometido el crimen haya aceptado se competencia o; c) Que el Estado del que es nacional el acusado haya aceptado su competencia.

El cumplimiento de estos nexos será imprescindible en caso de que la situación haya sido remitida por un Estado Parte o por el propio Fiscal (vía ordinaria), pero no será preciso si la situación ha sido remitida por el CS (vía extraordinaria de atribución de su jurisdicción).

Finalmente, debemos destacar que los Estados al ratificar el ER aceptan ipso facto la competencia de la CPI y su competencia no puede ni ser excluida ni alterada de forma

\footnotetext{
${ }^{17}$ Escudero Espinosa, J.F., «Los poderes del Consejo de Seguridad y la Corte Penal Internacional en el Estatuto de Roma», Anuario de Derecho Internacional, núm. 19, 2003, págs. I85 a 262 y en especial pág. I94.

${ }^{18}$ Cfr., GutiérRez EsPadA considera que la denominación como Organización Internacional a la CPI «rechina en su aplicación a un tribunal de justicia» y lleva hasta el extremo el requisito de composición estatal al decir que «la Corte no está formada por Estados, sus miembros no son Estados sino jueces; ¿dónde está el elemento de la conformación esencialmente interestatal de las Organizaciones? ». Vid., GuTiÉRREz EsPADA, C., «La Corte de Roma (I998) como Institución Internacional», Anales de Derecho, núm. 22, 2004, págs. 59 a 98 y en especial pág. 97.
} 
unilateral por los Estados Partes, con la salvedad prevista en el art. I24 ER a la que nos referiremos al estudiar los crímenes de guerra (sistema de opting out) ${ }^{\text {19 }}$.

\section{III.2. Límites a su competencia}

El art. I ER determina genéricamente que la CPI está facultada para ejercer su jurisdicción «sobre las personas respecto de los crímenes más graves de trascendencia internacional», de lo cual se deduce que solo tendrá competencia si se trata de personas físicas-naturales, crímenes más graves y que tengan trascendencia internacional (relacionar el art. I ER con el I7.I.d ER).

El ER es cauteloso a la hora de otorgarle competencia y el mismo tasa en su art. 5.I los crímenes de los que podrá conocer -crimen de genocidio, los crímenes de guerra, los crímenes de lesa humanidad y crímenes de agresión-, sometiéndose así al principio de legalidad.

Por esa razón, pese a que no son los únicos crímenes de derecho internacional existentes $^{20}$-crimen de terrorismo-, si serán los únicos sobre los que tendrá competencia, en consonancia con el principio de nullum crimen sine lege $e^{2 \mathrm{~T}}$ (art. $22 \mathrm{ER}$ ).

También supone una limitación a su competencia el principio de complementariedad previsto en el párrafo Io $^{\circ}$ del Preámbulo ER. Éste implica que la CPI sólo ejercerá su jurisdicción cuando las jurisdicciones nacionales competentes no la ejerciten o, cuando lo hagan de forma inadecuada con el objetivo de evitar que la persona comparezca ante la justicia o que se le sustraiga de su responsabilidad penal ${ }^{22}$.

Por esa razón y vinculado con el principio de ne bis in idem, en el art. I7 ER se prevé que la CPI resolverá su inadmisibilidad, entre otros motivos, si el Estado que tiene jurisdicción ya realizó una investigación sobre el mismo y no inició acción penal; ya enjuició a la persona presuntamente responsable o; si se encuentra realizando una investigación o enjuiciamiento del mismo.

Sin embargo, el principio de complementariedad, como señaló DIEZ DE VELASCO ${ }^{23}$, no supone la supremacía de las jurisdicciones nacionales, ya que se otorga a la CPI la

\footnotetext{
I9 Márquez Carrasco, M.C., «Alcance de la jurisdicción de la Corte Penal Internacional: jurisdicción universal o nexos jurisdiccionales aplicables», en CARrillo SAlCEdo, J.A. (Coord.), La criminalización de la barbarie: La Corte Penal Internacional, CGPJ, Madrid, 2000, págs. 365 y 366.

${ }^{20}$ En el art. Io ER se refleja la intención de sus redactores de no abordar todos los crímenes de derecho internacional, estableciendo que «nada de lo dispuesto (...) se interpretará en el sentido de que limite o menoscabe de alguna manera las normas existentes o en desarrollo del derecho internacional para fines distintos del presente Estatuto».

${ }^{21}$ En el DI penal la costumbre internacional también es fuente de derecho, por ese motivo, como bien apunta DíAz Soto, J.M.: «el aforismo nullum crimen sine lege es remplazado por nullum crimen sine iure», («Una aproximación al crimen internacional de agresión», Derecho Penal y Criminología: Revista del Instituto de Ciencias Penales $y$ Criminales, núm. 99, 20I4, págs. II a 60 y en especial pág. I8).

${ }^{22}$ DíEZ de Velasco, M., Las Organizaciones Internacionales, I6ª ed., Madrid, Tecnos, 20ıо, pág. 466.

${ }^{23}$ Ibid., pág. 466.
} 
competencia de pronunciarse sobre su propia competencia en caso de duda -principio Kompetenz-Kompetenz- (art. I9.I ER) y puede revocar el valor de cosa juzgada de una sentencia nacional, para ocuparse nuevamente de un asunto, si estima que la jurisdicción nacional no ha actuado conforme al interés de la justicia (art. $20 \mathrm{ER}$ ).

\section{III.3. Competencias}

\section{III.3.I. Ratione personae}

La CPI ejerce su competencia sobre las personas (art.I ER) físicas o naturales (25.I ER) si las mismas son mayores de I8 años (art. 26 ER). Además el art. 24.I ER veta la irretroactividad personal y lo conecta con el principio de irretroactividad de la ley penal desfavorable en su apartado segundo.

El ER establece la responsabilidad de las personas físicas con alcance general -sin distinción alguna basada en el cargo- (art. 27.I ER), de modo que las «inmunidades y las normas de procedimientos especiales que conlleve el cargo oficial de una persona (...), no obstarán para que la Corte ejerza su competencia» (art. 27.2 ER). Este precepto implica la aplicación del principio de igualdad ante la ley penal internacional.

Cierto es que parece evidenciarse una contradicción entre los arts. $98^{24}$ y 27 ER, sin embargo no se puede interpretar el art. 98 ER en el sentido de que se garantice la impunidad de determinados crímenes en función de su autoría, dado que dicha interpretación frustraría la finalidad del $\mathrm{ER}^{25}$. Por ese motivo, el artículo 98 «deberá interpretarse de buena fe conforme al sentido corriente (...) y teniendo en cuenta su objeto y fin» ${ }^{26}$.

Sin embargo, el verdadero problema resulta del uso indebido que se pretende dar del art. 98 ER por parte de algunos Estados, en especial Estados Unidos ${ }^{27}$, para suscribir acuerdos bilaterales de inmunidad - Bilateral Immunity Agreements- con otros Estados. Además, pese a la existencia de los erróneamente denominados «Acuerdos Relativos al Artículo 98 del Estatuto de Roma», se ha señalado que el art. 98 ER no fue redactado con la intención de permitir la celebración de nuevos acuerdos basados en el mismo, sino que sólo

\footnotetext{
${ }^{24}$ Art. 98 ER: «I. La Corte no dará curso a una solicitud de entrega o de asistencia en virtud de la cual el Estado requerido deba actuar en forma incompatible con las obligaciones que le imponga el derecho internacional con respecto a la inmunidad de un Estado o la inmunidad diplomática de una persona o un bien de un tercer Estado (...). 2. La Corte no dará curso a una solicitud de entrega en virtud de la cual el Estado requerido deba actuar en forma incompatible con las obligaciones que le imponga un acuerdo internacional conforme al cual se requiera el consentimiento del Estado que envíe para entregar a la Corte a una persona sujeta a la jurisdicción de ese Estado (...)».

${ }^{25}$ SCHEFFER, D.: «Article 98 (...) does not seek to deny the Rome Statute's core purpose of fighting impunity (...)», [«Article 98 (2) of the Rome Statute: America's Original Intent», JICJ, núm. 3, 2005 , DOI. Io.1093/jicj/mqio39, págs. 336].

${ }^{26}$ Arts. 3I y 32 de la Convención de Viena de I969 sobre el Derecho de los Tratados.

${ }^{27}$ Véase al respecto el contenido de la Ley que sancionó Estados Unidos de Protección del Personal de Servicio Estadounidense (American Servicemembers' Protection Act).
} 
e pretendía evitar los conflictos legales que podrían surgir debido a los acuerdos ya existentes entre Naciones ${ }^{28}$.

\section{III.3.2. Ratione materiae}

En esta sede nos vamos a ocupar de los «crímenes más graves de trascendencia para la comunidad internacional» (art.I ER) y veremos cuáles son los orígenes, definición, estructura y requisitos de cada uno de ellos, para lo cual tendremos en cuenta los Elementos de los Crímenes $^{29}$ ya que ayudan a la Corte a interpretar y a aplicar los artículos (art. 9.I ER).

\section{III.3.2.I. Crimen de Genocidio}

Este crimen ha sido considerado «el crimen de los crímenes» ${ }^{\circ \circ}$ y es el primero en aparecer en la lista del artículo 5 ER. La noción jurídica de genocidio se atribuye a Raphäel Lemkin y proviene del vocablo griego «genos» (tribu, raza) y de la raíz latina «cide» (matar).

El genocidio ha sido definido como «una denegación del derecho de existencia de grupos humanos enteros» ${ }^{31}$ o como un conjunto de actos que tienen como propósito «destruir total o parcialmente un grupo nacional, étnico, racial, religioso» (Art. 607 CP). Sin embargo, la definición dada por el art. 6 ER proviene del art. 2 de la Convención para la Prevención y Sanción del Delito de Genocidio de 9 de diciembre de 1948 y su redacción coincide con la de los arts. 4 y 2 del Estatuto del TPIY y TIPR, respectivamente.

El art. 6 ER consta de una serie de actos que serán constitutivos de genocidio siempre y cuando sean «perpetrados con la intención de destruir total o parcialmente a un grupo nacional, étnico, racial o religioso como tal». Por tanto, para estar ante un crimen de genocidio deben cumplirse una serie de requisitos ${ }^{32}$ :

a) Que el autor cometa alguno de los actos enumerados del artículo 6 ER.

b) Que la víctima sea un grupo nacional, étnico, racial o religioso como tal (y ningún otro, de ahí su naturaleza discriminatoria).

c) Que los comportamientos vayan destinados a destruir (física o biológicamente) ${ }^{33}$ total o parcialmente a alguno de los grupos anteriormente mencionados.

\footnotetext{
${ }^{28}$ Los acuerdos a los que se refiere son: a) Status of Mission Agreements (SOMAs) y, b) Status of Forces Agreements (SOFAs).

${ }^{29}$ Doc. PCNICC/2000/I/Add.2, Elementos de los Crímenes.

${ }^{30}$ TPIR, Prosecutor v. Kambanda, de 4 de Septiembre de I998 (Caso núm. ICTR 97-23-S), Judgement and Sentence, $\mathbb{1}$ I6.

${ }^{31}$ AGnu, Resolución 96 (I), de II de diciembre de I946.

${ }^{32}$ Bosly, H. y VAndermeersch, D., Génocide, crimes contre l humanité et crimes de guerre face à la justice. Les juridictions internationales et les tribunaux nationaux, $2^{\mathrm{a}}$ ed., Bruselas, Bruylant, 20I2, pág. 27.

${ }^{33}$ TPIY, Prosecutor v. Radislav Kristic, de I9 de abril de 2004 (Caso núm. IT-98-33-A), Judgement, Appeals Chamber, $\int 24$ y 25.
} 
d) Que exista una dolus specialis.- Este último requisito, la intencionalidad ${ }^{34}$ como elemento subjetivo, implica la existencia de una intención específica ${ }^{35}$ de «destruir total o parcialmente a un grupo nacional, étnico, racial o religioso como tal» y contribuye a determinar su especial gravedad, configurándose, per se, como una cláusula-umbral ${ }^{36}$.

\section{III.3.2.2. Crímenes de lesa humanidad}

En segundo lugar nos encontramos con los crímenes de lesa humanidad, también denominados crímenes contra la humanidad y cuyo nacimiento se puede situar en la Declaración de 28 de mayo de I9I5 en la que se describieron las masacres de la población armenia en Turquía como «crímenes contra la humanidad» ${ }^{37}$, aunque no fue hasta 1945 con la redacción de la Carta del Tribunal de Nüremberg cuando se recogió un listado de crímenes lesa humanidad ${ }^{38}$.

Estos crímenes se han definido como «los atentados contra bienes jurídicos individuales fundamentales (...) cometidos, tanto en tiempo de paz como de guerra, como parte de un ataque generalizado o sistemático realizado con la participación o tolerancia del poder político de iure o de facto» ${ }^{39}$.

El art. 7 ER consta de una doble estructura: un elemento de contexto o chapeau que son los elementos que identifican y definen por sí este crimen y una lista de actos inhumanos que deben ser cometidos en ese contexto. Así el art. 7 ER entiende por crímenes de lesa humanidad cualquiera de los actos inhumanos que enumera «cuando se cometa como parte de un ataque generalizado o sistemático contra una población civil y con conocimiento de dicho ataque».

\footnotetext{
${ }^{34}$ Nótese que el artículo 6 ER hace mención a la intención específica del crimen pero nada dice sobre los motivos del mismo. En este sentido véase Schabas, W., Genocide in International Law, Cambridge, Cambridge University Press, 2000, pág. 245 .

${ }^{35}$ Aмвоs, K., «What does intent to destroy in genocide mean?», International Review of the Red Cross, vol. 9I, núm. 87,2009 , págs. 833 a 858 y en especial pág. 834 .

${ }^{36}$ TPIR, Prosecutor v. Akayesu, de 2 de septiembre de I998 (Caso núm. ICTR-96-4-T), Judgment, Chamber I, $\llbracket 498$. Por razones prácticas no es posible una mayor extensión sobre esta cuestión, pero véanse en sentido contrario a lo expuesto, aquellos autores que entienden que la intención debe ser interpretada en un sentido más amplio en virtud del concepto de dolo eventual y del art. 30 ER, entre otros ,GIL GIL, A., «El concepto de intención en los delitos de resultado cortado. Especial consideración del elemento volitivo de la intención», RDPCUNED, núm. 6, 2000, págs. I03 a I38.

${ }^{37}$ TPIY, Prosecutor v. Tadic, de 7 de mayo de I997(Caso núm. IT- 94-I-T), Opinion and Judgment, Trial Chamber, \6I8.

${ }^{38}$ Robinson, D., «Defining «Crimes Against Humanity» at The Rome Conference», AJIL, Vol. 93. núm. I, I999, págs. 43 a 47 y en especial pág. 44). (Disponible en: http://www.jstor.org/stable/2997955, última consulta el 4/05/20I6. En el mismo sentido véase también la sentencia del TPIY, Prosecutor $v$. Tadic, de 7 de mayo de I997, \6I8, set. cit.

39 Gil Gil, A., «Los crímenes contra la humanidad y el genocidio en el Estatuto de la Corte Penal Internacional», en Амвоs, K., (Coord.), La nueva justicia penal supranacional. Desarrollos post-Roma, Valencia, Tirant Lo Blanch, 2002, pág. 94.
} 
Por tanto, para estar ante un crimen de lesa humanidad es necesario que se den las siguientes condictio sine qua non ${ }^{40}$ :

a) Ataque generalizado o sistemático contra una población civil. El test sistemáticogeneral hace referencia al nivel de gravedad que los hechos han de revestir. Es decir, se trata de una cláusula-umbral que establece la gravedad resultante de los hechos a través de dos criterios alternativos, uno cuantitativo y otro cualitativo, en función de si el criterio de referencia es el carácter sistemático o el ataque generalizado. Cierto es que al inicio se consideró la posibilidad de establecer una formula conjuntiva entre ambos criterios pero, finalmente, el ER acogió la formula disyuntiva aunque se agregó el requisito de que dicho ataque fuese dirigido contra la población civil $^{4 \mathrm{r}}$.

La sistematicidad, debe referirse a la comisión de los crímenes bajo un cierto plan preconcebido ${ }^{42}$ o bajo una política determinada -policy element- ${ }^{43}$ ya que «ningún ataque que se realice de forma fortuita pued(e) constituir un contexto válido en donde se desarrolle el crimen contra la humanidad» ${ }^{44}$. Sin embargo, la política no se limita a la realizada por un Estado, sino que también se extiende a la que pueda llevar a cabo una organización que de facto tenga el control del territorio ${ }^{45}$. Así, se permite incluir los crímenes cometidos por grupos terroristas, grupos armados insurrectos, separatistas, etc.

Por otro lado, la generalidad hace referencia a una serie de actos dirigidos contra una multiplicidad de personas ${ }^{46}$, excluyendo aquellos actos que se dirijan contra una sola persona o sean aislados, con independencia de que sean inhumanos ${ }^{47}$.

b) Conocimiento de ese ataque.. Se exige que «el autor haya tenido conocimiento de que la conducta era parte de un ataque generalizado o sistemático dirigido contra una población civil» ${ }^{48}$, configurándose como un elemento de intencionalidad especial ${ }^{49}$.

${ }^{40}$ TPIY, Prosecutor v. Tihomir Blaki, de 3 marzo del 2000 (Caso núm. IT-95-I4-T), \ 203.

${ }^{41}$ El requisito de que el ataque este necesariamente dirigido contra una población civil ha sido objeto de críticas. Vid., TPIY. Prosecutor v. Kupreskic, de I4 enero 2000 (Caso núm. IT-95-I6-T), Judgment, Trial Chamber, 『547. Véase también la interesante reflexión que realiza AMBOS, K., «Crímenes de Lesa Humanidad...», loc. cit., pág. 108.

${ }^{42}$ Schabas W., Genocide..., op. cit., pág. 207. En el mismo sentido véase Prosecutor v. Kayishema and Ruzindana (Caso núm. ICTR-95-I-T), Judgement, 2i de mayo de I999, 『94.

${ }^{43}$ Bassiouni, M.C., Crimes against Humanity..., op. cit., pág. 24.

${ }^{44}$ LiÑán LAFUente, A., «La tipificación del crimen de persecución en el Estatuto de Roma...», loc. cit., pág. 8.

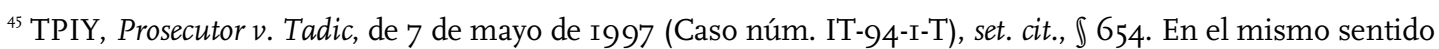
véase Quel LóPEZ, F., «La competencia material de los Tribunales Penales Internacionales: consideraciones sobre los crímenes tipificados», en ESCOBAR HERNÁNDEZ, C. (Ed.), Creación de una jurisdicción penal internacional, Madrid, BOE, Colección Escuela Diplomática núm. 4, 2000, págs. 75 a I04 y en especial pág. 92.

${ }^{46}$ Robinson, D.: «Widespread requires large-scale action involving a substantial number of victims», («Defining Crimes Against Humanity...», loc.cit., pág. 47).

${ }^{47}$ Para un análisis en profundidad del requisito subjetivo del crimen de lesa humanidad véanse los párrafos 770 a 782 de la sentencia CPI, Prosecutor v. Katanga, de 7 de marzo de 2014 (ICC-oI/O4-OI/O7), Judgment, Trial Chamer II.

${ }^{48}$ Doc. PCNICC/2000/I/Add.2 (2000), Elemento de los crímenes, art. 7, crímenes Lesa Humanidad: Introducción. 
Finalmente, se ha reconocido que no es preciso que el ataque este en conexión con un conflicto armado ${ }^{50}$ ni que se vincule con motivos discriminatorios ${ }^{5 \mathrm{I}}$, superando de ese modo el concepto restringido del Estatuto del TMIN ${ }^{52}$.

\section{III.3.2.3. Crímenes de guerra}

El tercero de los crímenes previstos en el ER son los crímenes de guerra y, pese a que fueron los primeros crímenes reconocidos, también fueron los más problemáticos a la hora de incluirlos dentro de su competencia. Sin embargo, a pesar de las divergencias existentes, el consenso llegó y estos se recogieron de forma detallada en el art. 8 ER empleando la acepción ya contenida en los cuatro Convenios de Ginebra de 1949 -relativos al DIH y al Derecho de la Guerra- y en los Protocolos Adicionales I y II de I977.

El citado artículo tiene la misma estructura que el del art. 6 ER de forma que se compone de un chapeau y de la enumeración de actos inhumanos. Además, se introdujo una cláusula-umbral consistente en que dichos crímenes se debían cometer «como parte de un plan o política o como parte de la comisión en gran escala de los mismos» $»^{53}$.

El art. 8.2 ER prevé un largo listado de actos constitutivos de crímenes de guerra, sin embargo los supuestos se pueden sistematizar en torno a cuatro categoría ${ }^{54}$ que se articulan sobre la distinción entre conflicto armado de carácter internacional (CAI) y conflicto armado no internacional (CANI) ${ }^{55}$.

a) Dentro de los CAI se incluyen:

- Las infracciones graves de los Convenios de Ginebra de i2 de agosto de 1949 (art. 8.2.a) que serán aquellos «actos contra personas o bienes protegidos por las disposiciones del Convenio de Ginebra pertinente» entre los que cabe mencionar el homicidio

${ }^{49}$ Respecto a la mens rea o elemento intencional hay que trasladar el debate surgido con anterioridad en relación con el crimen de genocidio.

5o LiÑán LAFUente, A., «La tipificación del crimen de persecución en el Estatuto de Roma y su primera aplicación jurisprudencial en el Tribunal Híbrido Internacional de Timor Oriental», Revista Electrónica de Ciencia Penal Y Criminología, núm. IO-I2, 2008, págs. I a 62 y en especial pág. 4.

(Disponible en: http://criminet.ugr.es/recpc/ıo/recpcıo-I2.pdf, última consulta el I9/05/20I6).

En el mismo sentido véase Robinson, D., «Defining Crimes Against Humanity...», loc.cit., pág. 46.

${ }^{51}$ Ibid., pág. 46.

${ }^{52}$ Cfr., con el art. 6.c) del Estatuto del TPIY en donde se consideraba crimen contra la humanidad una serie de «actos inhumanos cometidos contra población civil antes de la guerra o durante la misma; la persecución por motivos políticos, raciales o religiosos (...)». Cursiva añadida.

${ }^{53}$ En los párrafos 924 y siguientes de la sentencia CPI, Prosecutor v. Thomas Lubanga, de I4 de marzo de 2012 (ICC-oI/O4-OI/०6), Judgment, Trial Chamber I, se analizan los requisitos objetivos y subejtivos de este crimen. Por otra parte, se ha reconocido que en todo caso debe existir un policy element pero se ha matizado su alcance. Vid., TPIY, Prosecutor v. Kordic, 26 de febrero de 200 I (IT-95-I4/2-T), \I82.

${ }^{54}$ Pignatelli Meca, F., «La Corte Penal Internacional», en Rodríguez Villasante y Prieto, J.L. (Coord.), Derecho Internacional Humanitario, $2^{\text {a }}$ ed., Valencia, Tirant lo Blanch, 2007, pág.825.

${ }^{55}$ Art. 2 común a los Convenios de Ginebra de I949: será un CAI cuando dicho conflicto «surja entre dos o varias Altas Partes Contratantes», entendiendo por tales a los Estados. Art. 3 común de los Convenios de Ginebra: será un CANI cuando dicho conflicto «surja en el territorio de una de las Altas Partes Contratantes» y se complementa con lo dispuesto en el art. I del Protocolo Adicional II. 
intencional, la tortura o tratos inhumanos, el causar deliberadamente grandes sufrimientos o atentar gravemente contra la integridad física o la salud, etc.

- Las «violaciones graves de las leyes y usos aplicables en los conflictos armados internacionales» (art. 8.2.b). Esta categoría es una especie de «cajón de sastre» en donde se pueden incluir aquellas violaciones graves del DIH distintas de las infracciones graves. Se incluyen entre otros actos el dirigir intencionalmente ataques contra la población civil en cuanto tal, contra personas civiles que no participen directamente en las hostilidades, contra bienes civiles, atacar o bombardear ciudades o edificios que no estén defendidos y que no sean objetivos militares, utilizar de modo indebido la bandera blanca, emplear veneno o armas envenenadas, emplear gases asfixiantes, tóxicos o similares, etc.

b) En relación con los CANI se incluyen:

- «Las violaciones graves del art. 3 común a los cuatro convenios de Ginebra de I2 de agosto de i949» que serán aquellos «actos cometidos contra personas que no participen directamente en las hostilidades, incluidos los miembros de las fuerzas armadas que hayan depuesto las armas y las personas puestas fuera de combate por enfermedad, herida, detención o por cualquier otra causa» entre los que cabe mencionar los atentados contra la vida y la integridad corporal, los ultrajes contra la dignidad personal, las condenas dictadas sin previo juicio, etc.

- Otras «violaciones graves de las leyes y los usos aplicables en los conflictos armados que no sean de índole internacional» (art. 8.2.c y e), en los que se incluirían normas procedentes del Protocolo II de I977 y otras contenidas en el Reglamento de la Haya de I907; los actos en él previstos son similares a los recogidos en el art. 8.2.b.

Sin embargo, pese a que en 2010 como consecuencia de la Revisión de Kampala ${ }^{56}$ se ampliaron los supuestos tipificados bajo la denominación de CAI, tal y como señala PÉREZ CEPEDA $^{57}$, resulta criticable que el grado de protección que se establezca sea menor que para los CAI, dado que, a la postre, el objetivo perseguido es el mismo: la protección de la persona humana en una situación de conflicto armado.

Por su parte, también ha sido objeto de críticas la cláusula de opting-out prevista en el art. I24 ER mediante la cual se permite a un Estado que, en el momento de hacerse parte del ER, declare que no aceptará su competencia en relación con los crímenes de guerra durante un periodo de siete años.

\footnotetext{
${ }^{56} \mathrm{RC} /$ Res.5, de Io de junio de 20IO, publicada en el BOE núm. 227, de I8 de septiembre de 2014 .

${ }^{57}$ Pérez Cepeda, A. I., «Crímenes de guerra. Especial referencia al caso Couso», Revista Penal, núm. I5, 2005, págs. I05 a 136 y en especial pág. IIO.

(Disponible en: http://www.uhu.es/revistapenal/index.php/penal/article/viewFile/237/228, última consulta el i9/05/20i6). En el mismo sentido Lirola Delgado, I. y Martín Martínez. M. M., La Corte Penal Internacional. Justicia versus Impunidad, Barcelona, Ariel, 200I, pág. I29.
} 


\section{III.3.2.4. Crimen de agresión}

El reconocimiento de este crimen no hubiera sido posible sin la afirmación del principio de la ilegitimidad de la guerra y la prohibición de la amenaza y del uso de la fuerza en las relaciones internacionales (art. 2.4 CNU) -configurada como norma de ius cogens-. Por ese motivo, al hablar del crimen de agresión es necesario hacer referencia al acto de agresión, acto que se encuentra regulado por el DI desde principios del siglo XX con la intención de evitar que los Estados recurrieran a la guerra.

La tipificación del este crimen fue muy complicada. La primera vez que se reconoció su existencia fue en el art. 6.a) del Estatuto de Londres de 8 de agosto de I945 bajo la denominación de «crímenes contra la paz» -enfatizaba la responsabilidad del individuo- y más tarde en la Resolución 33I4 (XXIX) de I4 de diciembre de I974 de la AGNU -incidía en los aspectos de acto de Estado-.

$\mathrm{Su}$ conceptualización fue debatida desde el minuto cero e incluso durante la Conferencia de Roma había Estados que abogaban por su exclusión del ER. Finalmente se incorporó bajo el alegato de que serviría tanto para disuadir y prevenir la comisión de dichos crímenes en el futuro como para reafirmar que las guerras de agresión son un crimen de Derecho Internacional ${ }^{5}$, sin embargo, dada la falta de consenso, se consideró conveniente postergar en el tiempo su tipificación hasta que se alcanzara un acuerdo en torno a su definición y las condiciones bajo las que la CPI ejercería su competencia.

El crimen de agresión se prevé en el art. 5.I.d) ER y en su siguiente apartado, hasta la conferencia de Kampala, se disponía que la CPI únicamente ejercería su competencia respecto dicho crimen «una vez que se apruebe una disposición de conformidad con los artículos I2I y I23 en que se defina el crimen y se enuncien las condiciones en las cuales lo hará $»^{59}$ y se estableció que transcurridos siete años desde la entrada en vigor del ER se abriría la posibilidad a cualquier Estado Parte de proponer enmiendas al ER (arts. I2I y I23 ER). Así el ER otorgaba a la CPI, hasta entonces, una mera una mera competencia virtual o formal al respecto ${ }^{60}$.

La definición de este crimen llegó tarde, pero llegó. En la Conferencia que tuvo lugar el iı de junio de 20 Io en Kampala se decidió adoptar la Resolución RC/RES. 6 mediante la cual se definió el crimen de agresión, incluyéndose en el art. 8 bis ER, y se recogieron las condiciones para el ejercicio de la jurisdicción en el art. I5 bis y ter $\mathrm{ER}^{6 \mathrm{r}}$.

\footnotetext{
${ }^{58}$ Además, como expone DíAz Soto, J.M.: «resultaba ilógico que se pretendiera estatuir una Corte Internacional con competencias sobre los crímenes más graves de trascendencia para la comunidad internacional en su conjunto, pero se dejara de la do el crimen que desde Nüremberg fue catalogado como el crimen internacional supremo», («Una aproximación...», loc. cit., pág. 2I).

${ }^{59}$ La enmienda contenida en el Anexo I de la Resolución RC/Res.6, relativa al crimen de agresión, suprime el artículo 5.2 ER.

${ }^{60}$ Escobar Hernández, C., «La Corte Penal Internacional..., loc. cit., núm. 2I, 2003, pág. I3.

${ }^{61}$ Resolución RC/Res.6, de II de junio de 20I0. Vid., LO 5/20I4, de I7 de septiembre, por la que se autoriza la ratificación de las Enmiendas al Estatuto de Roma de la Corte Penal Internacional, relativas a los crímenes de guerra y al crimen de agresión, hechas en Kampala el io y iı de junio de 20 Io (BOE núm. 227, de I8 de septiembre de 20I4).
} 
Así, según el art. 8.i bis se entiende por crimen de agresión aquel cometido por una persona que esté «en condiciones de controlar o dirigir efectivamente la acción política o militar de un Estado» y que «planifica, prepara, inicia o realiza un acto de agresión que por sus características, gravedad y escala constituya una violación manifiesta de la Carta de las Naciones Unidas» ${ }^{62}$.

Es decir, dicho artículo introduce los siguientes requisitos para la tipificación del crimen de agresión:

a) La cláusula de liderazgo.- Se exige que los autores controlen de modo efectivo la acción política o militar del Estado agresor. Además este crimen posee una característica única, distinta del resto de crímenes ya que, mientras el bien jurídico protegido en los demás es el ser humano, en los crímenes de agresión lo que se pretende defender es la soberanía Estatal y su integridad territorial.

b) Acto de agresión.- Es definido como «el uso de la fuerza armada por un Estado contra la soberanía, la integridad territorial o la independencia política de otro Estado, o en cualquier otra forma incompatible con la Carta de las Naciones Unidas (...) ${ }^{63}$ y recoge una serie de estos actos constitutivos de acto de agresión ${ }^{64}$.

c) El umbral de gravedad o la naturaleza del acto de agresión.- Éste se compone de un criterio cualitativo relativo a las características del acto y de otro cuantitativo en función de la gravedad y escala ${ }^{65}$, ya que no todo uso ilícito de la fuerza armada por parte de un Estado contra otro supone la atribución de responsabilidad penal bajo un crimen de agresión, sino solo aquellos actos que por sus características, gravedad y escala supongan una violación manifiesta de la CNU (art. 8 bis 2).

Sin embargo, ¿en qué casos el uso de la fuerza armada alcanza el nivel de crimen de agresión? La expresión «violación manifiesta» de la CNU lejos de ser esclarecedora, crea dudas al respecto, por ese motivo debemos traer a colación el art. 46.2 de la Convención de Viena sobre el Derecho de los Tratados en el que se entiende por violación manifiesta aquella que «resulta objetivamente evidente para cualquier Estado que proceda en la materia conforme a la práctica usual y de buena fe». Además, en el entendimiento número

\footnotetext{
${ }^{62}$ Su redacción es reflejo de la definición de crimen contra la paz prevista en el Estatuto del TMIN.

${ }^{63}$ El art. 8 bis 2 establece como requisito de la agresión que el uso de la fuerza armada sea empleada por un Estado. Esta cuestión ha sido debatida y, siguiendo a DíAZ SoTO, J.M.: «el carácter estatal del ejercicio de la fuerza armada no es un requisito sine qua non del acto de agresión, de modo que lege ferenda nada obstaría para que se admitiera la responsabilidad penal por un crimen de agresión de los dirigentes de organizaciones armadas no estatales», («Una aproximación...», loc. cit., pág. 27).

${ }^{64}$ Se discute si la lista de actos enunciados es, o no, taxativa. Aquellos que argumentan a favor de su carácter restrictivo defienden su posición sobre la base del principio de legalidad y sobre el art. 7.I. k ER, en el que se incluye una cláusula abierta de «otros actos inhumanos de carácter similar», a diferencia del presente caso. Por su parte, aquellos que consideran no es un listado taxativo defienden su posición alegando que el listado proviene, en parte, de la Resolución 33I4 en donde se establecía expresamente que «la enumeración de los actos mencionados (...) no es exhaustiva».

${ }^{65}$ Doc. ICC-ASP/6/20/Add.I, \24. «Delegations supporting this threshold clause noted that it would appropriately limit the Court's jurisdiction to the most serious acts of aggression under customary international law, thus excluding cases of insufficient gravity and falling within a grey area (...)».
} 
7 de la resolución RC/RES.6, de II de junio de $2010^{66}$, se dispone que para determinar si el acto de agresión viola o no de forma manifiesta la CNU se han de tener en cuenta los tres elementos «características, gravedad y escala» y «ninguno de los elementos puede bastar por sí solo para satisfacer el criterio de violación manifiesta».

En cuanto a las condiciones para el ejercicio de la jurisdicción en relación con el crimen de agresión, éstas se prevén en el art. I5 bis -remisión por parte del Fiscal o de un Estado Parte- y ter -remisión por parte del CS-.

De lo dispuesto en dichos artículos resultan destacables los siguientes aspectos. Por una parte se dispone que la CPI sólo podrá ejercer su competencia respecto a este crimen «después del I $\mathrm{I}^{\mathrm{o}}$ de enero de 20I7» y «únicamente (...) respecto de crímenes de agresión cometidos un año después de la ratificación o aceptación de las enmiendas por treinta Estados Partes» (art. I5 bis 2 y I5 ter 2ER). Es decir, una vez obtenidas las 30 ratificaciones la CPI tendrá competencia para enjuiciar a los nacionales de los Estados Partes con independencia de que hayan ratificado o no la enmienda, lo cual contrasta con lo dispuesto en el artículo I2I.5 ER ${ }^{67}$, si bien es cierto que se establece la posibilidad de presentar una declaración de no aceptación de su competencia (art. I5 bis 4 ER).

Por otro lado también resulta curioso que se deje al CS la determinación de si existe o no un acto de agresión y, en caso negativo, el Fiscal solo podrá iniciar los procedimientos de investigación si, en el plazo de 6 meses, la Sección de Cuestiones Preliminares lo autoriza y el CS no decida lo contrario en virtud del art. I6 ER (art. I5 bis 8 ER).

\section{III.3.2.5. ¿Crimen de terrorismo internacional?}

Durante años el terrorismo ha sido una amenaza evidente en España ${ }^{68}$, sin embargo, la preocupación por esta lacra se ha ido extendiendo a otros Estados y en general, a la Comunidad Internacional. Así, se ha reconocido que «los actos terroristas (...), constituyen graves crímenes de trascendencia para la comunidad internacional» ${ }^{69}$. Sin embargo, existe una grave laguna legal, en la medida en que, a pesar de que el terrorismo es «una de las amenazas más graves para la paz y la seguridad internacionales» ${ }^{70}$, hasta la

\footnotetext{
${ }^{66}$ Anexo III de la Resolución RC/Res.6, de iı de junio de 2010.

${ }^{67}$ Cfr., Art. I2I.5 ER: «Las enmiendas a los artículos 5, 6, 7 y 8 (...) entrarán en vigor únicamente respecto de los Estados Partes que las hayan aceptado (...). La Corte no ejercerá su competencia respecto de un crimen comprendido en la enmienda cuando haya sido cometido por nacionales o en el territorio de un Estado Parte que no haya aceptado la enmienda». Cursiva añadida.

${ }^{68}$ La Ley Orgánica 2/20I5, de 30 de marzo, publicada en el BOE núm. 77, de 3I de marzo de 20I5, modificó el Código Penal Español en materia de delitos de terrorismo. La definición de qué se entiende por terrorismo en España se prevé en el art. 573 CP.

${ }^{69}$ Vid., Anexo I apartado E del Acta final de la Conferencia diplomática de plenipotenciarios de las Naciones Unidas sobre el establecimiento de una corte penal Internacional (A/CONF.I83/IO).

${ }^{70}$ Resoluciones del CS 2 I70 (20I4), de I5 de agosto de 2014 [S/RES/2I70 (20I4)] y 22I4 (20I5), de 27 de marzo de 2015 [S/RES/22I4 (20I5)].
} 
fecha no ha habido consenso para convenir su definición en el ámbito internacional ${ }^{71}$ y por tanto no ha sido posible su prohibición categórica como tal.

Como hemos analizado, el art. 5 ER no incluye el terrorismo internacional como crimen autónomo competencia de la CPI -no fue posible su tipificación-, sin embargo, si podrá ser competente si el acto terrorista es subsumible dentro de alguna de las categorías de crímenes de las que la CPI es competente ${ }^{72}$. Además, nada obsta a que en un futuro la CPI pueda ejercer su competencia sobre el terrorismo como crimen autónomo si se amplía su competencia -como ha ocurrido respecto al crimen de agresión-.

Pese a ello, dada la situación actual en la que nos encontramos, en la que el terrorismo constituye uno de los peores flagelos para la sociedad $d^{73}$, no sería descabellado pensar en la creación de un tribunal penal internacional con competencia exclusiva sobre esta materia. De hecho, ya existe una propuesta de proyecto por parte de España y Rumanía para su creación y, aunque es pronto para determinar si será o no fructífera -y para determinar cuál será su relación con las jurisdicciones nacionales y con la CPI-, lo que es evidente, es que generará debate entre la sociedad y por tanto se creará un caldo de cultivo que permita estipular sus elementos esenciales ${ }^{74}$.

\section{III.3.3 Ratione temporis}

Para que la CPI tenga competencia será preciso también que reúna los requisitos relativos a su competencia temporal. En este sentido se analizaran dos cuestiones.

\footnotetext{
${ }^{71}$ Como señala RodRíguez-VILLASANTE y PRIETO, J.L.: «el carácter polisémico del término 'terrorismo' supone que pued(a) ser abordado desde múltiples puntos de vista que se corresponden con diversas ramas científicas e incluso, dentro de las ciencias jurídicas y sociales, puede adquirir significados muy diversos» [«Terrorismo y Derecho Internacional Humanitario», en RodríguEZ-VILLASANTE Y PRIETO, J.L. (Coord.), Derecho Internacional Humanitario, op. cit., pág. 2I7].

${ }^{72}$ Mateus-Rugles, A., y Martínez-Vargas, J. R., «Derecho Penal Internacional y Terrorismo: ¿crimen de Derecho Internacional? », Revista facultad de derecho y ciencias políticas, vol. 40, núm. II3, págs. 38I a 4I4 y en especial pág. 387 .

${ }^{73}$ Desde el inicio del Siglo XXI el número de víctimas por terrorismo ha incrementado de forma exponencial, así en el año 2000 hubo aproximadamente unas 3.300 víctimas mientras que en 2014 el número se incrementó hasta alcanzar aproximadamente las 32.600. Además, el mayor ascenso se produjo en 2014 ya que el número total de víctimas del terrorismo incrementó en un $80 \%$ respecto el año anterior. Las estadísticas también reflejan que la actividad terrorista está concentrada en cinco países que representan el $78 \%$ de las víctimas por terrorismo y son Irak, Nigeria, Afganistán, Pakistán y Siria, mientras que dicha actividad en países de occidente, en comparación con los anteriores mencionados, es muy reducida. Así, entre el año 2000 y el 20I4, el número de víctimas por terrorismo en países occidentales ha representado un $0,5 \%$ del total de víctimas, porcentaje en el que no se incluye el ataque terroristas del in de septiembre de 20 II (aumentaría a un 2,6\%). En el estudio tampoco se incluyen los atentados del I3 de noviembre de 2015 en París ni el de 22 de marzo de 2016 en Bruselas, ya que sólo se analiza hasta el año 2014 .

Datos obtenidos del Índice de Terrorismo Global de 2015 elaborado por el Instituto para la Economía y la Paz. Véase Global Terrorism Index 2015, measuring and understanding the impact of terrorism. (Disponible en: http://economicsandpeace.org/wp-content/uploads/20I5/II/Global-Terrorism-Index-20I5.pdf, última consulta el 10/06/2016).

${ }^{74}$ Para mayor abundamiento sobre esta cuestión véase PANTALEO L. y RibBELINK, O., «The Establishment of a Special Court against Terrorism». European Journal of Intenational Law, Talk!

(Disponible en: http://www.ejiltalk.org/the-establishment-of-a-special-court-against-terrorism/, última consulta el ı०/06/2016).
} 
a) El principio de irretroactividad temporal.- El ER recogió este principio en su art. II ER al disponer que la CPI «tendrá competencia únicamente respecto de crímenes cometidos después de la entrada en vigor» del ER y, si un Estado decide hacerse parte después de que el ER haya entrado en vigor, la CPI solo podrá ejercer su competencia sobre el mismo después de la entrada en vigor del ER respecto de ese Estado (art. II.2 que habría que poner en conexión con el I26.2 ER).

Sin embargo toda regla general tiene alguna excepción y en el caso que nos ocupa ésta se recoge en el art. I2.3 ER, mediante el cual se permite que un Estado acepte la competencia de la CPI -respecto a un caso concreto y mediante una declaración ad hocantes de haber adquirido la condición de Estado Parte.

b) El principio de imprescriptibilidad de los crímenes.- Este principio se configura como la otra cara de la moneda en el ejercicio de su competencia temporal y lo encontramos en el art. $29 \mathrm{ER}^{75}$.

\section{La Corte Penal Internacional y el Consejo de Seguridad: el mantenimiento de la paz y la seguridad internacionales}

A día de hoy, tras los acontecimientos acaecidos y los cambios a los que el DI se ha visto sometido en las postrimerías del siglo XX, los pilares básicos de la Sociedad Internacional se sustentan sobre el mantenimiento de la paz y seguridad internacionales y el respeto y garantía de los derechos humanos fundamentales y de ahí que no fuese cuestión baladí el reforzar, en la actividad de NN.UU, los vínculos existentes entre promoción y protección de los derechos humanos por una parte y paz y seguridad internacionales por un otra ${ }^{76}$.

La CPI se vincula con las NN.UU y, en especial, con el CS que es el órgano que tiene conferida «la responsabilidad primordial de mantener la paz y la seguridad internacionales» (art. 24.I CNU) ${ }^{77}$. Al hablar del CS deberemos tener presente el derecho de veto del que disponen cinco de sus miembros en relación con las cuestiones de fondo ${ }^{78}$. Sin embargo, cabe plantearse cuáles son las relaciones existentes entre la CPI como tribunal

${ }^{75}$ La imprescriptibilidad de los crímenes tiene trascendencia en la medida en que no todos los ordenamientos la prevén.

${ }^{76}$ BAssiouni, C.: «The challenge to a new world order remains to be met, but justice is its foundation. Indeed, without justice, there can be no lasting peace (...)», [«The United Nations Commission of Experts Established Pursuant to Security Council Resolution 780 (I992) », AJIL, Vol. 88, núm. 4, I994, págs. 753 a 805 y en especial pág. 805].

77 Como señala Wilmshurst, E.: «The United Nations Charter gives the council a mandate for the maintenance of peace and security. And the preamble to the Statute of the Court recognizes that crimes within the Court's jurisdiction can threaten the world's peace and security», [«The International Criminal Court; The Role of the Security Council», en Politi, M. y Nesi, G. (Eds.), The Rome Statute of the International Criminal Court. A challenge to impunity, Alserhot (England), Asghate, 2002, pág. 325].

${ }^{78}$ Art. 23 CNU: «El Consejo de Seguridad se compondrá de quince miembros de las Naciones Unidas. La República de China, Francia, la Unión de las Repúblicas Socialistas Soviéticas, el Reino Unido de la Gran Bretaña e Irlanda del Norte y los Estados Unidos de América, serán miembros permanentes del Consejo de Seguridad». 
internacional penal permanente y el CS como órgano político inserto en NN.UU, ya que pese a la indisoluble conexión existente entre los objetivos de ambos, la CPI es una institución independiente de las NN.UU ${ }^{79}$.

\section{IV.r. Legitimación del Consejo de Seguridad para remitir situaciones a la Corte}

El CS dispone de legitimación activa en la medida en que el art. I3.b) le permite remitir a la CPI cualquier situación que considere subsumible en el art. 5 ER, siempre y cuando se cumplan una serie de requisitos:

a) Actuación del CS «con arreglo a lo dispuesto en el Capítulo VII de la Carta de Naciones Unidas».- Es preciso que el CS se encuentre ante un asunto que él mismo, previamente, haya calificado como «una amenaza a la paz, un quebrantamiento de la paz o un acto de agresión» en virtud dl art. 39 de la CNU.

b) Remisión de una situación en que parezca haberse cometido uno o varios de esos crímenes.- El CS lo que hace es remitir al Fiscal de la CPI una «situación», pero no remite «el asunto» para que la CPI lo juzgue directamente, puesto que ésta será la que decida si ha se ha cometido, o no, algún crimen y si procede, o no, iniciar la investigación y/o enjuiciamiento.

\section{2. Facultad del Consejo de Seguridad para ampliar la competencia de la Corte}

Esta facultad está íntimamente ligada con la anterior y, en esta sede, analizaremos en qué medida incide la intervención del CS al remitir una situación a la CPI.

Por una parte, como ya hemos visto, no será preciso que se cumplan los las condiciones previas para el ejercicio de la competencia de la CPI previstas en el art. I2 ER. Se trata de un supuesto excepcional dado que es el único caso en el que un asunto puede ser sometido a la jurisdicción de la CPI incluso sin que el Estado interesado haya ratificado el Estatuto, otorgando jurisdicción ad hoc a la CPI. Además constituye el único supuesto de verdadera competencia universal de la CPI.

En relación con la competencia temporal de la CPI, no existe ninguna disposición en el ER en la que se haga distinción en función de quién remita el asunto a la CPI, por ese motivo se sobrentiende que solo tendrá competencia «después de la entrada en vigor del presente Estatuto» (art. II ER). Sin embargo, ¿puede el CS remite a la CPI una situación producida con anterioridad a su propia creación? La contestación debería ser afirmativa en la medida en que el CS puede crear un tribunal ad hoc y ex post factum, por lo que sería

79 Cfr. Gutiérrez EspadA, C.: «La independencia (...) implica actuar sin subordinación alguna a otra autoridad (...)», sin embargo, como veremos, hay «disposiciones que nos hacen dudar de esa afirmación. Así, el Consejo de Seguridad de Naciones Unidas puede remitir asuntos y pedir la suspensión de una investigación», [«La Corte de Roma (1998)... », loc. cit., pág. 66].

En el mismo sentido se expresa ELARABY, N.: «Its Independence and power can only be guaranteed when its proceedings are clearly beyond the scope of the political influence of the Security Council», [«The role of the Security Council and the Independence of International Criminal Court: Some Reflections» en PoLITI, M. y Nesi, G. (Eds.), The Rome Statue..., op. cit., pág. 46]. 
posible que el CS sólo solicitara a la CPI su enjuiciamiento en virtud de la regla qui potest plus, potest minus. Si bien es cierto que en este caso sería necesario el consentimiento por parte de la CPI ya que la base de su competencia no residiría en el ER sino en una resolución del CS.

Por último, debemos plantearnos si el principio de complementariedad sigue «vigente» o, si por el contrario en este caso las jurisdicciones nacionales ceden y prevalece sobre jurisdicción de la CPI. La doctrina no es unánime al respecto, algunos autores defienden que el carácter complementario de la jurisdicción de la CPI se mantiene ${ }^{80}$, mientras que otros entienden que, efectivamente, en este caso prevalece la jurisdicción de la CPI sobre nacionales. Posicionándome más a favor de esta última línea de defensa y siguiendo a ESCUDERO ESPINOSA «la remisión de situaciones por el CdS aparece excluida de las decisiones preliminares relativas a la admisibilidad que garantizan la aplicación del principio de complementariedad ${ }^{8}{ }^{8}$, lo cual implica que el principio de complementariedad en este caso decae ${ }^{8_{2}}$.

Cierto es que el CS ha hecho uso de esta facultad en dos ocasiones ${ }^{8_{3}}$, sin embargo resulta criticable la posición que dicho órgano ha adoptado frente a la actual crisis que se está viviendo en la República Árabe Siria, ya que pese a la existencia de un conflicto armado -sumamente complejo- en el cual se han producido graves violaciones de derechos humanos $^{84}$, algunos de sus miembros permanentes -China y Rusia- han ejercido su derecho a veto para impedir llevar a Siria ante la CPI, pese a que, como bien señala RUIZ DE LOS PAÑos, «el Consejo de Seguridad no puede utilizar el sistema de seguridad colectiva más que para un exclusivo fin: el mantenimiento de la paz y seguridad de la comunidad internacional, evitando emplear los poderes del Capítulo VII para atender a los intereses particulares y exclusivos de algunos de sus Estados miembros» ${ }^{85}$.

${ }^{80}$ Véase entre otros Gutiérrez EspadA, C., «La Corte Penal Internacional y las Naciones Unidas. La discutida posición del Consejo de Seguridad», ADI., 2002, págs. 3 a 6I y en especial pág. 30.

(Disponible en: http://dadun.unav.edu/bitstream/roI7I/22490/I/ADI_XVIII_2002_oI.pdf, última

consulta el 29/05/2016).

${ }^{81}$ EsCUdero Espinosa, J.F., «Los poderes del Consejo de Seguridad...», loc. cit., págs. 232. En el mismo sentido y con una explicación más profunda a partir del art. I8 ER véase CARDONA Lloréns, J., «La Corte Penal Internacional y el Mantenimiento de la Paz y Seguridad Internacionales», en Gómez Colomer, J.L., GonZÁLEZ CusSAC, J.L. y CARdona Lloréns, J. (Coords.), La Corte Penal Internacional..., op. cit., págs. 67 a 69 .

${ }^{82}$ Cfr., la incidencia de la remisión de una situación por el CS sobre el principio de complementariedad, se ve atemperada por el art. I9 ER, en el que se prevé la posibilidad de los Estados de impugnar la admisibilidad de una causa concreta.

${ }^{83}$ S/RES/I593 (2005), Resolución I593 (2005) del CS, de 3I de marzo de 2005, sobre la remisión de la cuestión de Darfur a la CPI y S/RES/I970 (20II) y Resolución I970 (20II) del CS, de 26 de febrero sobre la remisión de la cuestión de Libia a la CPI. Véase también el Anexo adjunto al trabajo.

${ }^{84} \mathrm{~A} / \mathrm{RES} / 70 / 234$, Resolución de la Asamblea General de NN.UU de 23 de diciembre de de 23 de diciembre de 20I5, sobre la situación de los derechos humanos en la República Árabe Siria.

${ }^{85}$ Ruiz De Los PaÑos, A., «La prohibición del uso de la fuerza: sistema institucionalizado de seguridad colectiva», en Rodríguez-Villasante y PRIETo, J.L. (Coord.), Derecho Internacional..., op. cit., pág. 9i9. 


\section{IV.3. Facultad de suspensión del Consejo de Seguridad}

El art. I6 ER otorga la prerrogativa al CS de permitirle suspender la investigación o enjuiciamiento de la situación que este siendo tratada por la CPI.

Nótese la paradójica situación del caso que se plantea: se considera que hay determinados supuestos en los que se entiende que para mantener o restablecer la paz, es conveniente no enjuiciar los responsables de los crímenes del art. 5 ER, lo que se traduce en dejar impunes a los autores de los crímenes más graves de trascendencia para la comunidad internacional en su conjunto. Si a simple vista esta situación parece, per se, incomprensible, la misma se agrava si se contrasta con lo dispuesto en el art. I.I de la CNU en virtud del cual, para mantener la paz y la seguridad internacionales de forma estable, es necesario actuar conforme a los principios de la justicia y del DI, erradicando la impunidad de los autores de los crímenes más graves ${ }^{86}$.

Sin embargo, esta facultad de suspensión del CS se encuentra sometida, al menos aparentemente, a dos límites formales:

a) Adopción de una resolución formal.- El art. I6 ER exige que el CS actúe «de conformidad con una resolución aprobada con arreglo a lo dispuesto en el Capítulo VII de la Carta de las Naciones Unidas», lo que implica, que el CS califique previamente la situación bajo uno de los supuestos del art. 39 ER.

b) Límite temporal.- El CS puede solicitar a la CPI bien que no inicie una investigación o enjuiciamiento o bien que suspenda por un plazo de doce meses una investigación o enjuiciamiento ya iniciados, pero dicha petición puede ser renovada por el CS en las mismas condiciones.

Sin embargo, ¿‘cuál es el límite de su temporalidad? De la dicción literal del art. I6 ER se deduce sin esfuerzo interpretativo que, en principio, se puede suspender ad infinitum mediante prórrogas de tiempo iguales, ya que no se establecen límites respecto al número de prórrogas que se pueden realizar. Sin embargo, siguiendo a GUTIÉRREZ ESPADA, «una interpretación a ras de letra de un texto (...) contradice la esencia de conceptos claves del mismo» ${ }^{87}$.

Por otra parte, el límite temporal, en principio parecería referirse a aquellos casos en los que las investigaciones o el enjuiciamiento ya han sido iniciados, puesto que para que el CS pueda «suspender» la investigación o enjuiciamiento de un caso, sería lógico entender que el mismo debía haberse iniciado previamente. No obstante, de los trabajos preparatorios $^{88}$ y de la práctica parece deducirse lo contario, lo cual implica permitir al CS declarar incompetente a la CPI a priori, impidiéndole que inicie una investigación respecto

${ }^{86}$ Cfr., Borjas Monroy. A.C., «La potestad del Consejo de Seguridad para solicitar a la Corte Penal Internacional la suspensión de una investigación o de un enjuiciamiento», Revista Derecho del Estado, núm. 27, 20II, págs. I23 a I52 y en especial pág. I28.

${ }^{87}$ GutiérRez EsPadA, C., «La Corte de Roma (I998)... », loc. cit., pág. 9I.

${ }^{88}$ El texto actual del ER es más restrictivo que el recogido en el art. 23.3 del Proyecto de la CDI de i994 en el que se decía, en vez de investigaciones o enjuiciamientos «que ya haya iniciado», que «ninguna investigación puede iniciarse (...) que derive de una situación que estuviere siendo tratada» por el CS. 
a situaciones que aún no se han producido, véanse como ejemplo las dos -criticablesresoluciones del CS: la Resolución I422 (2002) y la Resolución I487 (2003).

\section{IV.4. El Consejo de Seguridad como garante de la cooperación Estatal}

La cooperación de los Estados es imprescindible para que la CPI pueda investigar y enjuiciar los crímenes de los que es competente ${ }^{89}$, de hecho la CPI puede «formular solicitudes de cooperación a los Estados Partes», e incluso puede invitar a cualquier Estado no Parte a que preste asistencia «sobre la base de un arreglo especial, un acuerdo con ese Estado o de cualquier otra manera adecuada», así como solicitar a cualquier organización intergubernamental «la información o documentos», así se prevé en el art. 87.I.a), 5.a) y 6 respectivamente ${ }^{90}$.

Por su parte, en el art. 87.7 ER se establece que si un Estado Parte -o no Parte (art. 87.5 ER) - no colabora con la CPI, ésta puede remitir la cuestión a la AEP o al CS, pero en este último caso solo si el asunto fue remitido por el CS, por lo tanto, en el resto de supuestos, será la AEP la que podrá actuar de acuerdo con las competencias que el ER le reconoce. Sin embargo, el art. II2.I.f) ER se limita a decir que la AEP «examinará cuestiones relativas a la falta de cooperación (...)», sin especificar qué medidas puede adoptar. Se deduce de ello que ésta podrá hacer recomendaciones al Estado reticente a cumplir o a otros Estados Partes para que ayuden a cambiar la situación, pero no dispone de poderes coercitivos por sí sola para obligar a que cooperen. Por ello, la AEP podrá dirigirse al CS para que este determine si la ausencia de cooperación supone una «amenaza a la paz» (39 CNU) o al menos si «puede poner en peligro el mantenimiento de la paz y seguridad internacionales» (art. $34 \mathrm{CNU}$ ), en cuyo caso el CS estaría facultado para exigir la cooperación y adoptar las medidas que considere necesarias para tal fin (art. 4I CNU para las medidas coercitivas no armadas y $42 \mathrm{CNU}$ para las armadas $)^{91}$, aunque el fundamento de tal obligación sería una resolución del CS, no el ER.

\section{IV.5. El consejo de Seguridad y la determinación de un acto de agresión}

La existencia de un acto de agresión, como sabemos, resulta imprescindible para que la CPI pueda conocer del crimen de agresión, sin embargo no debemos confundir estos dos términos. Nótese que para estar ante un crimen de agresión será necesario que se

\footnotetext{
${ }^{89}$ España aprobó la LO I8/2003, de Io de diciembre, de cooperación con la Corte Penal Internacional (BOE, núm. 296, de in de diciembre de 2003).

${ }^{\circ}$ Como exponía CASSESE, A. M.: «State cooperation is crucial to the effectiveness of judicial process. The decisions, orders and request of International criminal courts can only be enforced by others, namely national authorities (...)», porque, como explica, «Unlike domestic criminal courts, international tribunals have no enforcement agencies at their disposal (...)», («The Statute of the International Criminal Court: Some Preliminary Reflections», EJIL, núm. I, I999, págs. I44 a I7I y en especial pág. I64).

${ }^{91}$ El CS debe decidir qué hacer con los Estados que no cooperan, en este sentido véase TPIY, Prosecutor $v$. Blaskic, de 29 de octubre de 1997 (Caso núm. IT 95-I4), Judgement on the request of the Republic of Croatia for review of the Decision of Trial Chamber II of I8 July I997, Appeals Chamber, \33. «It is primarily for its parent body, the Security Council, to impose sanctions, if any, against a recalcitrant State, under the conditions provided for in Chapter VII of the United Nations Charter».
} 
produzca la efectiva concurrencia de un acto de agresión, ergo crimen de agresión y acto de agresión no son sinónimos, sino que este último es el fundamento del primero.

Sin embargo, dejando aparte el crimen de agresión, la CNU entiende por actos de agresión como una categoría diferente de las amenazas y quebrantamientos a la paz de su artículo 39, configurándose así como una de las posibles formas de quebrantamientos de la paz cuya calificación queda a discreción del CS la calificación a dar ${ }^{92}$.

En realidad, la calificación que el CS escoja solo tiene relevancia para determinar las responsabilidades, puesto que si se califica como acto de agresión su autor podrá ser juzgado ante la CPI, mientras que la mera calificación como amenaza a la paz o quebrantamiento a la paz no es suficiente para atribuir la responsabilidad penal, salvo que se logre individualizar y subsumir en alguna de las categorías de crímenes del art. 5 ER ${ }^{93}$.

\section{Conclusiones}

Primera. Los Estados y la Guerra han convivido en una especie de simbiosis a lo largo de la Historia. De hecho, esta última se venía configurando como atributo de la soberanía estatal y por ello el recurso a la fuerza armada no era inusual. Sin embargo, tras las atrocidades acaecidas durante las dos Guerras Mundiales, se inició una nueva era en materia de defensa de los derechos humanos, pero para la consecución de tal hito, era preciso, en primer lugar, el reconocimiento del individuo como sujeto de DI. Así, además de aprobarse diversos textos en los que se reconocían derechos y se imponían deberes al individuo, la Comunidad Internacional, concienciada de que determinadas conductas -por su gravedad- no podían dejarse sin reproche penal, exigió el establecimiento de mecanismos internacionales que garantizaran el cumplimiento del DI e impidieran la impunidad.

Segunda. En correlación con lo expresado anteriormente, se crearon diversos tribunales -TMIN, TMIT, TPIY, TPIR- que, pese a haber sido fuertemente criticados por las características de las que se les dotó, constituyeron los antecedentes más notables de la CPI, la cual ha logrado superar las deficiencias de aquellos primeros tribunales. En este sentido, podemos afirmar que la CPI es una institución jurídicamente revolucionaria en la medida en que sanciona los crímenes más graves de trascendencia internacional y ejerce su competencia con independencia de quién sea el autor de los mismos; no se trata, por tanto, de un tribunal excepcional, ad hoc y ex post factum en el que los vencedores imponen la ley a los vencidos, sino que se estamos ante un tribunal permanente, con vocación de universalidad y con personalidad jurídica propia al que los Estados deciden voluntariamente someterse y, de ahí, la grandeza (y debilidad) de la CPI y la necesidad de cooperación por parte de los Estados.

\footnotetext{
$9^{92}$ Véase al respecto Remiro Brotons, A., «Agresión, crimen de agresión, crimen sin castigo», FRIDE, núm. IO, 2005, págs. I a I7 y en especial págs. 3 y 4.

${ }^{93}$ La calificación no tendrá trascendencia a la hora de determinar las medidas a adoptar (uso de la fuerza o no), puesto que los artículos 4I y 42 CNU no hace distinción entre las medidas que el CS puede escoger para el restablecimiento de la paz y la seguridad internacional en función de la calificación.
} 
Tercera. La existencia de la CPI -y por consiguiente del ER- no debe ser entendida en el sentido de que vacía de contenido las legislaciones penales de los Estados Partes, ni en sentido de que absorbe las competencias de las jurisdicciones nacionales respecto a aquellos crímenes sobre los que la misma tiene potencial competencia, sino más bien todo lo contrario. Así debemos tener en cuenta, por una parte, que la entrada en vigor del ER provocó numerosas reformas legislativas en los Estados que lo ratificaron, precisamente para que, dado el caso, éstos pudieran asumir su competencia al respecto; por otra parte, debemos subrayar el carácter complementario de la CPI. Así las cosas, el ER y la CPI, lejos de configurarse como un texto que sustituye a las legislaciones nacionales y de una Corte que reemplaza a las jurisdicciones internas, se configuran como un mecanismo que alienta y promueve a las jurisdicciones nacionales para que cumplan con las responsabilidades que les incumben. Un ejemplo claro de que la CPI se somete al principio de complementariedad, es la sentencia dictada el pasado 30 de mayo de 2016 por las Cortes Extraordinarias Africanas en relación con los crímenes de lesa humanidad cometidos en Chad. De esta forma, se evidencia que la CPI sólo actuará como mecanismo de última ratio y lo hará con el objetivo de evitar la impunidad de aquellos crímenes que repugnan y conmueven a la humanidad.

Cuarta. La CPI, como Organización Internacional, presenta una serie de rasgos peculiares debido a que se le atribuyó la misión de enjuiciar a los autores de «los crímenes más graves de trascendencia internacional», es decir, se le encomendó la primordial tarea de proteger los valores esenciales de la Comunidad Internacional.

En la actualidad su labor se restringe al enjuiciamiento de crímenes de guerra, de genocidio, de lesa humanidad y de agresión (art. 5 ER); sin embargo, nada obsta a que en un futuro sus competencias se vean ampliadas al enjuiciamiento de otros crímenes internacionales, como podría ser el terrorismo internacional, crimen del que, a día de hoy, no podrá ser competente como crimen autónomo pero sí como crimen subsumible dentro de algunas categorías del artículo 5 ER si se dan los requisitos exigidos. Se trata de una cuestión que está en tela de juicio y habrá que estar a la expectativa de si prospera, o no, la propuesta hispano-rumana de creación del tribunal penal internacional con competencia exclusiva en esta materia y, en caso afirmativo, ver cómo interactuarían los diversos órganos jurisdiccionales.

Quinta. En consonancia con lo anterior, se puede apreciar la relación entre la CPI y NN.UU y en especial con el CS, ya que la competencia ratione materiae de la CPI está estrechamente vinculada con los «Propósitos y Principios» de la CNU y, en concreto, con el mantenimiento de la paz y seguridad internacionales y la promoción y protección de los derechos humanos.

Sexta. La relación entre la CPI, como Tribunal Internacional Penal permanente, y el CS, como órgano político de NN.UU, no está exenta de dificultades y críticas, sin embargo la autonomía que caracteriza a la CPI no puede traducirse en un desconocimiento de la realidad ya que, a la postre, ambos persiguen la consecución de fines comunes. 
Las cuestiones más debatidas al respecto son, por una parte, la posibilidad de que el CS pueda suspender la investigación o enjuiciamiento de un asunto sobre el que la CPI haya empezado a ocuparse -o no-, bajo el entendimiento de que existen determinados supuestos en los que, teóricamente, para mantener o restablecer la paz, es conveniente no enjuiciar a los responsables de los crímenes de mayor gravedad. Bajo mi punto de vista, estamos ante un supuesto totalmente paradójico que contradice, no solo el sentido común sino también la finalidad del propio ER de eliminar la impunidad. Por otro lado, también es causa de gran desasosiego el hecho de que los miembros permanentes del CS puedan ejercer su derecho de veto, normalmente amparados en intereses meramente políticos y económicos, para impedir que situaciones en las que claramente se están produciendo violaciones masivas y sistemáticas de derechos humanos sean llevadas ante la CPI -si los Estados no son Parte del ER- como es el actual caso de Siria.

Séptima. Finalmente, debemos traer a colación la existencia de un escepticismo fundado hacia la CPI que derivado fundamentalmente del ámbito geográfico al que parece ceñirse y de que, pese al elevado número de países que han ratificado el ER, otros de gran trascendencia -entre ellos algunos miembros permanentes del CS- no lo han ratificado y además han adoptado posturas intransigentes hacia la misma, como es el paradigmático caso de Estados Unidos.

Cierto es que lo anterior hace que se genere desconfianza sobre su imparcialidad y sobre su eficacia, sin embargo, en mi opinión, en la medida en que se trata de un mecanismo que pretende, entre otras cosas, preservar y proteger los derechos humanos y la justicia internacional, debería ser acogida con los brazos abiertos.

Por ello debemos tener en cuenta que la lucha contra la impunidad es todavía un proceso inacabado y que la CPI constituye sólo un eslabón en el sistema de la justicia internacional, sin embargo es alentador el recibimiento que ha tenido por parte de numerosos Estados, por lo que este avance, por pequeño que sea, no debería ser menospreciado y deberemos atender a los acontecimientos futuros para determinar hasta qué punto resulta efectiva, imparcial y de utilidad.

\section{Tabla de abreviaturas}

$\begin{array}{ll}\text { ADI } & \text { Anuario de Derecho Internacional } \\ \text { AEP } & \text { Asamblea de los Estados Partes } \\ \text { AGNU } & \text { Asamblea General de Naciones Unidas } \\ \text { AJIL } & \text { The American Journal of International Law } \\ \text { Art., arts. } & \text { Artículo, artículos } \\ \text { BOE } & \text { Boletín Oficial del Estado } \\ \text { CAI } & \text { Conflicto Armado Internacional } \\ \text { CANI } & \text { Conflicto Armado No Internacional } \\ \text { CDI } & \text { Comisión de Derecho Internacional } \\ \text { Cfr. } & \text { Cónfer, confróntese } \\ \text { CGPJ } & \text { Consejo General del Poder Judicial } \\ \text { Coord., Coords. } & \text { Coordinador, coordinadores } \\ \text { CNU } & \text { Carta de Naciones Unidas } \\ \text { CP } & \text { Código Penal }\end{array}$




\begin{tabular}{ll} 
CS & Consejo de Seguridad \\
DH & Derechos Humanos \\
DI & Derecho Internacional \\
DIH & Derecho humanitario \\
Dir. & Director \\
DOI & Digital Object Identifier \\
Ed., Eds. & Editor, editores \\
ed. & Edición \\
EJIL & European Journal of International Law \\
ER & Estatuto de Roma \\
FRIDE & Fundación para las Relaciones Internacionales y el Diálogo Exterior \\
Ibid. & Ibídem, en el mismo lugar \\
ICC & International Criminal Court \\
IT & International Tribunal \\
Loc. cit. & Locus citatum, lugar citado \\
NN.UU & Naciones Unidas \\
Op. cit. & Opus citatum, obra citada \\
RDPCUNED & Revista de Derecho Penal y Criminología \\
RECPC & Revista Electrónica de Ciencia Penal y Criminología \\
RIFP & Revista Internacional de Filosofía Política \\
Set. cit. & Sentencia citada \\
TMIN & Tribunal Militar Internacional de Nüremberg \\
TMIT & Tribunal Militar Internacional para el Extremo Oriente o \\
TPIR & Tribunal de Tokio \\
TPIY & Tribunal Penal Internacional para Ruanda \\
V. gr. & Tribunal Penal Internacional para la ex Yugoslavia \\
Vid. & Verbi gratia, por ejemplo \\
$\int$ & Véase \\
& Párrafo \\
\hline
\end{tabular}

